\title{
Prospective cross-sectional study on faecal immunochemical tests: sex specific cut-off values to obtain equal sensitivity for colorectal cancer?
}

\author{
Sietze T van Turenhout ${ }^{1 * \dagger}$, Frank A Oort ${ }^{1 \dagger}$, René WM van der Hulst ${ }^{2}$, Arjen P Visscher ${ }^{1,2}$, \\ Jochim S Terhaar sive Droste ${ }^{1}$, Pieter Scholten ${ }^{3}$, Anneke A Bouman ${ }^{4}$, Gerrit A Meijer ${ }^{5}$, Chris JJ Mulder ${ }^{1}$, \\ Leo GM van Rossum ${ }^{1,6}$ and Veerle MH Coupé ${ }^{7}$
}

\begin{abstract}
Background: Faecal immunochemical tests (FITs) are commonly used in colorectal cancer (CRC) screening. Diagnostic accuracy of FIT differs between males and females. This so far unexplained difference could result in a dissimilarity in screening outcome between both sexes. The aim of this study is to compare sensitivity and specificity of a FIT between males and females, and study potential explanatory variables.

Methods: In this cross-sectional study, data were prospectively collected. 3,022 subjects performed a FIT prior to complete colonoscopy. Sensitivity, specificity, and ROC curves were compared for both sexes. Potential explanatory variables of the relation between sensitivity and sex were explored.

Results: At all cut-off values, FIT sensitivity for CRC was higher (range 13-23\%) and specificity was lower (range 2-4\%) in males compared to females. At $75 \mathrm{ng} / \mathrm{ml}$, sensitivity for CRC was $93 \%$ in males compared to $71 \%$ in females ( $p=0.03)$, and specificity was $90 \%$ in males compared to $93 \%$ in females $(p=<0.05)$. For advanced adenomas, males had a slightly higher sensitivity and lower specificity (not significant). At $75 \mathrm{ng} / \mathrm{ml}$, sensitivity for advanced adenomas was $33 \%$ in males compared to $29 \%$ in females ( $p=0.46$ ), and specificity was $93 \%$ in males compared to $95 \%$ in females $(p=0.22)$. ROC curves were similar for both sexes, and equal combinations of sensitivity and specificity could be achieved by adjusting the cut-off values. For CRC, the difference in sensitivity could not be explained by age or location of the tumour.
\end{abstract}

Conclusions: FIT has a higher sensitivity and a lower specificity for CRC in males than in females. Equal test characteristics can be achieved by allowing separate cut-off values for both sexes. Location and age do not explain the observed differences in sensitivity.

Keywords: Colorectal cancer screening, Advanced adenoma, Fecal immunochemical test, Sex

\section{Background}

Colorectal cancer (CRC) is a leading cause of cancer related death worldwide [1]. Early detection by population screening is the most realistic approach to reduce CRCrelated death. Faecal immunochemical tests (FITs) are increasingly used as the primary screening test for CRC [2].

* Correspondence: s.vanturenhout@vumc.n

${ }^{\dagger}$ Equal contributors

'Department of Gastroenterology and Hepatology, VU University Medical Centre, Amsterdam, the Netherlands

Full list of author information is available at the end of the article
Recently, it was found that FITs have a higher sensitivity and lower specificity for advanced colorectal neoplasia in males compared to females [3]. Although diagnostic accuracy of a screening test is just one of several factors determining the efficiency of a screening programme, a difference in FIT characteristics between males and females could implicate disparities in the expected benefit from CRC screening. Such a difference may require tailored screening. Whether this difference reflects, for example, a dissimilarity in advanced neoplasia distribution or a difference in the age of onset of CRC, remains to be resolved. 
The aim of the present study is to investigate whether the sensitivity and specificity of a frequently used FIT for the detection of CRC and advanced adenomas differs between males and females, and whether this difference can be explained by age, location, number and/or size of neoplastic lesions.

\section{Methods}

\section{Study population}

For the current analysis, data were used from an ongoing study programme on FIT performance. This programme aims to answer several research questions and has been previously described extensively [4-6]. In short, individuals scheduled for elective colonoscopy in 5 participating medical centres were invited to participate and perform a FIT prior to colonoscopy. In addition to the exclusion criteria of these previous studies, individuals with an indication of visible rectal bleeding or anaemia were excluded from the analysis to minimize potential workup bias. Use of NSAIDs and/or aspirin was no exclusion criterium, and subjects were not advised on whether to continue this medication on the day of colonoscopy. The study was approved by the VU University Medical Centre Ethics Committee, Kennemergasthuis Ethics Committee, Sint Lucas Andreas Ethics Committee, Zaans Medical Centre Ethics Committee and Slotervaart Hospital Ethics Committee. All participants provided written informed consent.

\section{Study design}

In this cross-sectional study, data were collected prospectively. The test used was an automated FIT with quantitative results: OC-sensor ${ }^{\ominus}$ (Eiken Chemical Co., Tokyo, Japan). One experienced technician performed the analyses, and was kept unaware of the clinical data. All tests were analysed by using the OC sensor MICRO desktop analyser (Eiken Chemical co, Tokyo, Japan) [7]. A cut-off of $\geq 75 \mathrm{ng} / \mathrm{ml}$ is advised by the manufacturer. Here, haemoglobin concentrations of $\geq 50, \geq 75, \geq 100$, and $\geq 200 \mathrm{ng} / \mathrm{ml}$ of buffer solution were taken as cut-off values. These concentrations correspond to faecal haemoglobin concentrations of respectively $\geq 10, \geq 15, \geq 20$ and $\geq 40$ milligram of haemoglobin per gram of faeces.

\section{Colonoscopy and lesions}

Experienced gastroenterologists performed or supervised all colonoscopies. The endoscopists were unaware of the FIT result, in order to prevent investigator bias. Conscious sedation by midazolam was offered to all patients.

A colonoscopy was considered complete when the caecum was intubated with identification of the appendicle orifice and valvula Bauhini, or when an obstructing neoplasm was found. Quality control measures included documentation of colonic landmarks. Individuals in whom the bowel cleansing was insufficient, and individuals in whom the colonoscopy remained incomplete were excluded from analysis. However, if a barium enema, virtual colonography or second colonoscopy was performed within six months, evaluation of the colon was considered complete and the subject was included in analysis. The right colon was defined as the proximal part of the colon including caecum, ascending colon, right (or hepatic) flexure and transverse colon. The left colon was defined as the distal part of the colon including left (or splenic) flexure, descending colon, sigmoid and rectum $[8,9]$. In case of multiple neoplasia detected on colonoscopy, patients were classified based on the most advanced lesion found.

Tissue samples obtained at colonoscopy were sent to the department of pathology and evaluated according to current standards. Adenomas $\geq 1.0 \mathrm{~cm}$, adenomas with a villous component (i.e. tubulovillous or villous adenoma) or adenomas with severe/high-grade dysplasia were classified as advanced adenomas [10,11].

\section{Statistical analysis}

Using colonoscopy as the reference test, sensitivities and specificities of FIT were calculated for two definitions of colonoscopy outcome: (i) the presence of CRC and (ii) the presence of advanced adenoma. Sensitivity was defined as the proportion of positive test results in patients with the colonoscopy outcome under consideration. Specificity was calculated as the proportion of negative test results in patients with an outcome less severe than the outcome under consideration.

Sensitivity and specificity of FIT at different cut-off values were compared between males and females using the Fisher Exact test. Analyses were repeated for the symptomatic and screening/surveillance indication groups separately. Receiver Operating Characteristic (ROC) curves were plotted for both sexes separately and the Areas Under the ROC Curves (AUC's) were calculated, along with their 95\% confidence intervals. The 95\% confidence intervals were used to compare diagnostic capabilities.

To study whether sex dissimilarities are a reflection of differences in age, location and size or number of neoplastic lesions, a stratified analysis of $2 \times 2$ contingency tables was performed, with statistical testing using the Fishers Exact test. Age was dichotomized into subjects $<65$ and 65 or older. Location was divided in left and right sided lesions. The number of advanced adenomas was grouped as 1 or $>1$, and size was grouped $<10 \mathrm{~mm}$ or $\geq 10 \mathrm{~mm}$.

In addition, the effect of these covariates on the relation between test sensitivity (for CRC and advanced adenoma) and sex was studied in a multivariate logistic regression analysis. In this analysis, we aimed to estimate the independent effect of each factor after adjusting for the contributions of other variables in the model. Full multivariate models (i.e., forced entry with no variable 
selection) were used, because it was of interest to study the extent to which the coefficient of sex would be influenced when including other covariates in the model. The Wald test was used to detect significant factors in multivariate logistic regression analysis models. Age was used as continuous variable. To avoid dilution of the potential independent effect of location on FIT results, subjects with CRC on both sides of the colon, and subjects with advanced adenomas on both sides of the colon were excluded from the multivariate analysis. Stratified analyses and the multivariate analysis were performed for a FIT cut-off value of 50, 75 and $100 \mathrm{ng} / \mathrm{ml}$. The manuscript contains the results at the cut-off value of $75 \mathrm{ng} / \mathrm{ml}$. In the supplementary data, the results of multivariate logistic regression analysis for CRC and advanced adenomas are shown for the cut-off values of 50 and $100 \mathrm{ng} / \mathrm{ml}$. The variables studied for CRC and advanced adenomas were sex, age, and location of the lesion. Additionally, T-stage and presence of advanced adenomas were used as variables for predicting sensitivity for CRC. For advanced adenomas, the size and number of advanced adenomas were added to the analysis.

There was no correction of p-values to recognize that several tests of statistical significance were performed on data arising from individual patients, because the purpose of the research was to highlight any potential differences.

All analyses were performed with SPSS for Windows Version 20 (SPSS Inc., Chicago, USA).

\section{Results}

\section{Participants}

Between June 2006 and October 2010, 4,704 subjects returned a FIT and underwent colonoscopy. Of these, 1,682 were excluded for different reasons (see Figure 1), leaving 3,022 participants for analysis. As the first colonoscopy was incomplete in 107 participants, a second colonoscopy, barium enema or CT-colonography was needed to complete the colonoscopic evaluation. The mean age of the participants was 59.7 years (range 19-91 years, SD 12.6), and $45 \%$ was male. The indication for colonoscopy was evaluation of symptoms in $44 \%(1,331 / 3,022)$, screening or surveillance in $47 \%(1,412 / 3,022)$, and unspecified in $9 \%(279 / 3,022)$ (see Table 1). Characteristics of included males and females are shown in Table 2.

\section{Colonoscopy}

In $2.3 \%$ of the included subjects, CRC was found $(69 / 3,022)$ and in another $10.1 \%$ one or more advanced adenomas were detected (304/3,022; see Figure 1). From all subjects with CRC, $11.6 \%(8 / 69)$ also had one or more advanced adenomas. Males were found to have a higher prevalence of CRC $(45 / 1357=3.3 \%)$ than females $(24 / 1665=1.4 \%$; $\mathrm{p}=0.001)$. The distribution of CRC stages according to the TNM classification, is demonstrated in Figure 1. The
T-stage (Tumour-stage) distribution was $16 \%(11 / 69) \mathrm{T} 1$, 25\% (17/69) T2, 33\% (23/69) T3 and 6\% (4/69) T4. In 14 (20\%) individuals with CRC, T-stage was unknown due to preoperative radiotherapy, or was not determined because of disseminated disease at time of diagnosis. The prevalence of T1/T2 and T3/T4 tumours was comparable in males $(17 / 32=53 \%)$ and females $(11 / 23=48 \% ; \mathrm{p}=0.70)$.

\section{Positivity rates}

For the total population, the FIT positivity rate was $12.3 \%$ and $12.7 \%$ at a cut-off level of 50 and $75 \mathrm{ng} / \mathrm{ml}$, respectively. The positivity rate decreased with increasing cut-off values, to $6.8 \%$ at $200 \mathrm{ng} / \mathrm{ml}$. Males were found to have a higher positivity rate $(50 \mathrm{ng} / \mathrm{ml} ; 15.3 \%$, $75 \mathrm{ng} / \mathrm{ml} ; 12.7 \%$ ) compared to females $(50 \mathrm{ng} / \mathrm{ml} ; 9.8 \%$, $75 \mathrm{ng} / \mathrm{ml} ; 8.3 \%$, p-values $<0.001)$.

\section{Sensitivity and specificity}

In the total study population, the sensitivity for CRC at a cut-off value of 50 and $75 \mathrm{ng} / \mathrm{ml}$ was $88 \%$ and $86 \%$, respectively. Specificity was $90 \%$ and $92 \%$ at 50 and 75 $\mathrm{ng} / \mathrm{ml}$. For advanced adenomas, sensitivity and specificity were $35 \%$ and $92 \%$ at $50 \mathrm{ng} / \mathrm{ml}$ and $31 \%$ and $94 \%$ at $75 \mathrm{ng} / \mathrm{ml}$, respectively (see Table 3 ). At all cut-off values, males were found to have a higher sensitivity for CRC than females. The difference in sensitivity ranged from $13 \%$ to $23 \%$ and was largest and significant at the cut-offs 75 and $100 \mathrm{ng} / \mathrm{ml}$. More specifically, at $75 \mathrm{ng} / \mathrm{ml}$, sensitivity for CRC was $93 \%$ in males compared to $71 \%$ in females $(p=0.03)$. The specificity for CRC was significantly lower in males compared to females, but the difference was small (between 2.2 and 3.9\%, see Table 3). For advanced adenomas, the differences in sensitivity and specificity between males and females showed the same pattern as for CRC. However, the higher sensitivity in males was small (not significant, see Table 3). Only specificity of FIT in males at a cut-off value of $50 \mathrm{ng} / \mathrm{ml}$ was significantly lower than in female participants (see Table 3).

Results for the symptomatic and screening/surveillance indication groups separately are in line with results for the total population. In the group with symptomatic individuals, sensitivity for CRC at $75 \mathrm{ng} / \mathrm{ml}$ was $93 \%$ in males and $81 \%$ in females. In the screening/surveillance group these figures were $100 \%$ and $50 \%$ respectively. However, the screening/surveillance group consisted of only 14 carcinomas. The specificity for CRC at $75 \mathrm{ng} / \mathrm{ml}$ in the symptomatic group was in $92 \%$ males and $92 \%$ in females. In the screening/surveillance group these figures were $90 \%$ and 93\% respectively. For advanced adenomas, sensitivity at $75 \mathrm{ng} / \mathrm{ml}$ in the symptomatic group was $26 \%$ in males and in $32 \%$ females. These figures were respectively 33\% and $24 \%$ in the screening/surveillance group. In the symptomatic group, specificity for advanced adenomas at $75 \mathrm{ng} / \mathrm{ml}$ was $94 \%$ in males and also $94 \%$ in females. For the 


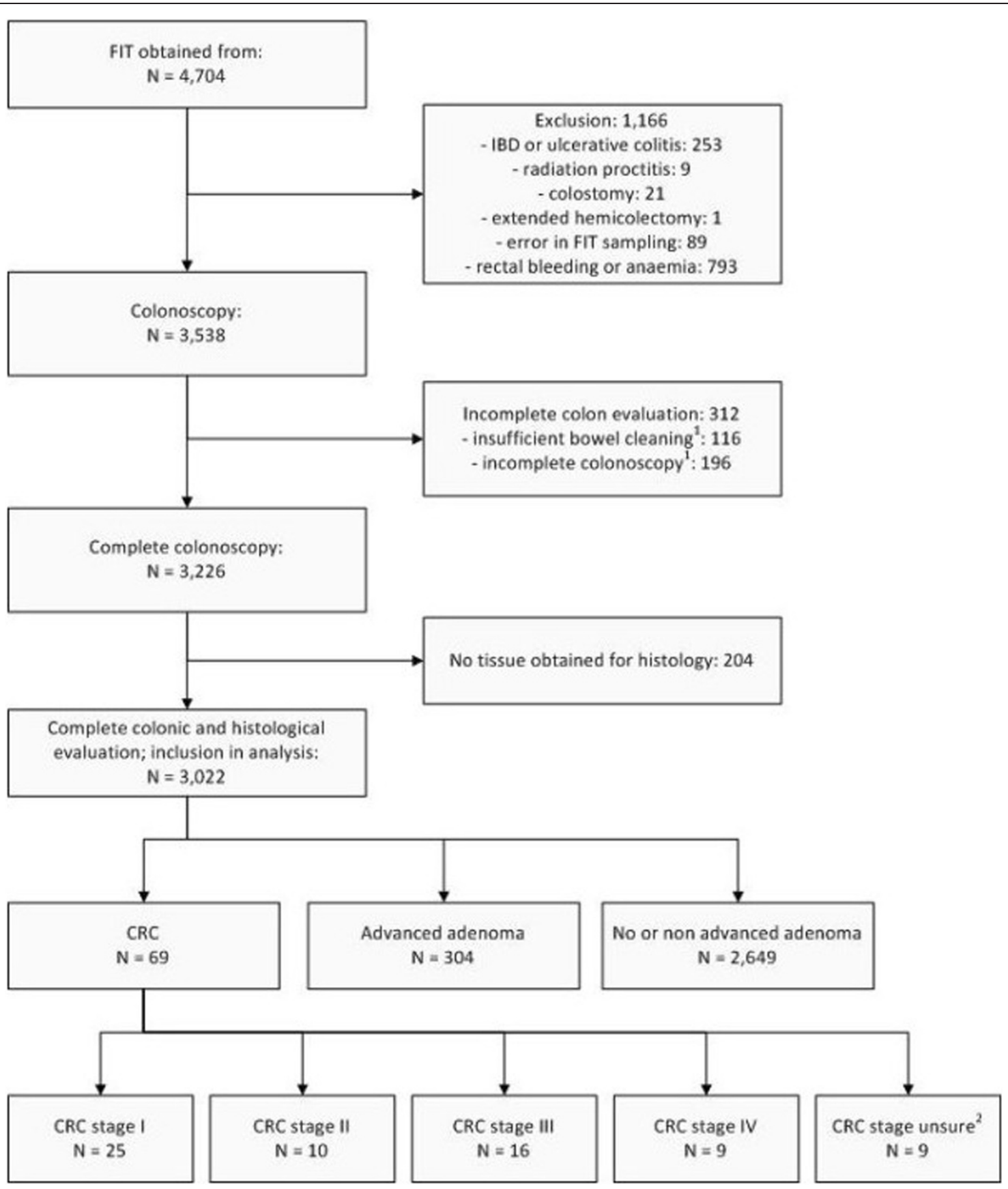

Figure 1 Study flow diagram. 'Incomplete colon evaluation in spite of possible additional evaluation by repeated colonoscopy, barium enema or virtual colonography within 6 months. ${ }^{2} \mathrm{CRC}$ stage remained unsure as these cases received pre-operative radiotherapy or due to disseminated disease exact classification remained unknown.

screening/surveillance group these figures were 93\% and $95 \%$ respectively.

\section{Receiver operating characteristic curves}

The test characteristics for males and females at each cut-off value are visualized in the ROC curves in Figures 2 and 3. The AUC's for CRC for males and females were 0.95 (95\% CI 0.909-0.985) and 0.90 (95\% CI
0.819-0.981) respectively. The ROC curves and AUC's for advanced adenoma were very similar between males and females (see Figure 3).

\section{The influence of potential explanatory variables}

In patients with CRC, males were found to have a higher FIT positivity rate than females $(50 \mathrm{ng} / \mathrm{ml} 93 \%$ vs. $79 \%$, 
Table 1 Primary indication for colonoscopy among 3,022 consecutive patients included for analysis of FIT characteristics according to sex

\begin{tabular}{lll}
\hline Indication group & Indication for colonoscopy & N \\
\hline Symptomatic & Weight loss & 88 \\
& Clinical suspicion of diverticulitis & 26 \\
& Clinical suspicion of IBD & 40 \\
& Abdominal pain & 355 \\
& Altered bowel habits & 548 \\
& Clinical or radiological suspicion & 54 \\
& of CRC & \\
& Diarrhoea & 128 \\
& Constipation & 92 \\
& Total & $\mathbf{1 , 3 3 1}$ \\
Screening \& surveillance & Average risk & 103 \\
& Familial history of CRC & 482 \\
& Lynch syndrome & 54 \\
& Polyp surveillance & 578 \\
& Post CRC surveillance & 195 \\
Other & Total & $\mathbf{1 , 4 1 2}$ \\
Grand total & Not specified/others & $\mathbf{2 7 9}$ \\
& & $\mathbf{3 , 0 2 2}$ \\
\hline
\end{tabular}

*This group includes individuals who were referred for colonoscopy as CRC was suspected on abdominal sonography, $\mathrm{CT} / \mathrm{MRI}$ scan or physical examination. $\mathrm{FIT}=$ faecal immunochemical test, IBD = inflammatory bowel disease, $\mathrm{CRC}=$ colorectal cancer.

Table 2 Characteristics of males and females with CRC and advanced adenomas included in comparative analysis of a FIT test

\begin{tabular}{lll}
\hline & Males & Females \\
\hline Total number of subjects & $\mathbf{1 , 3 1 2}$ & $\mathbf{1 , 6 4 1}$ \\
CRC & $\mathbf{N = 4 5}$ & $\mathbf{N}=\mathbf{2 4}$ \\
\hline Mean age & 68.0 years & 68.8 years \\
$\begin{array}{l}\text { Positive tests* } \\
\text { Location (left sided/right }\end{array}$ & $93 \%$ & $71 \%$ \\
$\begin{array}{l}\text { sided/missing) } \\
\text { Symptomatic/screening \& } \\
\text { surveillance/unknown }\end{array}$ & $67 \% / 31 \% / 2 \%$ & $71 \% / 29 \% / 0 \%$ \\
\hline $\begin{array}{l}\text { Advanced Adenoma } \\
\text { Mean age }\end{array}$ & $\mathbf{N}=\mathbf{1 6 4} / 18 \% / 18 \%$ & $67 \% / 25 \% / 8 \%$ \\
$\begin{array}{l}\text { Positive tests* } \\
\text { Location (left sided/right } \\
\text { sided/missing) }\end{array}$ & 63.9 years & $\mathbf{N}=\mathbf{1 4 0}$ \\
$\begin{array}{l}\text { Number of advanced } \\
\text { adenomas }>1\end{array}$ & $33 \%$ & 64.3 years \\
$\begin{array}{l}\text { Size of advanced } \\
\text { adenoma }>9 \text { mm }\end{array}$ & $29 \% / 36 \% / 9 \%$ & $64 \% / 29 \% / 7 \%$ \\
$\begin{array}{l}\text { Symptomatic/screening \& } \\
\text { surveillance/unknown }\end{array}$ & $28 \% / 54 \% / 18 \%$ & $38 \% / 45 \% / 17 \%$ \\
\hline
\end{tabular}

*Cut-off value $75 \mathrm{ng} / \mathrm{ml}$. CRC = colorectal cancer; FIT = faecal immunochemical test. $\mathrm{p}=0.08)$. This difference persisted when stratifying CRC by location ( $100 \%$ vs. $88 \%$ (left-sided) and $79 \%$ vs. $51 \%$ (right-sided)). Overall for males and females, left sided CRC was found to have a higher positivity rate (96\%) than right sided CRC $(71 \%, \mathrm{p}<0.05)$. However, within males and females with CRC, an equal proportion of cancers was left sided. In multivariate analysis, location and sex were found to be associated with FIT sensitivity for CRC (see Table 4 and Additional file 1: Tables S1 and S2 for cut-off values 50 and $100 \mathrm{ng} / \mathrm{ml}$ ). The univariate odds ratio for sex (OR 5.8, 95\% CI 1.3-25.0) was only mildly affected by the inclusion of location and age in the analysis (OR 6.2, 95\% CI 1.2-32.9). As such, the relation between sex and FIT sensitivity is not a result of differences in age of the patients or location of the tumour between males and females.

In individuals with advanced adenomas, males were found to have a slightly higher positivity rate than females (37\% vs. $33 \%$, n.s.). Left sided advanced adenomas were more frequently positive (38\%) than right sided lesions $(24 \%, \mathrm{p}=0.02)$. Also, subjects with more than one advanced adenoma were found to have a higher FIT positivity rate (63\%) than subjects with one advanced adenoma $(27 \%, \mathrm{p}<0.001)$. The same was found for subjects with an advanced adenoma $>9 \mathrm{~mm}(45 \%)$ compared to advanced adenomas $<10 \mathrm{~mm}(12 \%, \mathrm{p}<0.001)$.

In males, a slightly higher proportion of advanced adenomas was right-sided (40\% in males versus $32 \%$ in females) and was large in size (76\% in males versus $71 \%$ in females). In addition, in men multiple synchronous advanced adenomas were more common (21\% in males versus $17 \%$ in females, not significant). The distribution of these explanatory variables caused a shift in the OR for sex from 1.2 in the univariate analysis to 1.0 in the multivariate analysis, indicating that the small difference in sensitivity between males and females can be explained by differences in the size and number of advanced adenomas (see Table 4 and Additional file 1: Tables S1 and S2). In conclusion, the size and the number of advanced adenomas were important predictors of FIT positivity in advanced adenomas, but sex was not.

\section{Discussion}

In the present study, sensitivity and specificity of a frequently used FIT was assessed in males and females in a large cohort of subjects referred for colonoscopy. FIT was found to be more sensitive and less specific for CRC in men than in women. The areas under the ROC curves were similar for males and females. By using different cut-off values for both sexes, a similar sensitivity can be reached. The difference in sensitivity between the sexes could not be explained by age or location of the lesion. The sensitivity of FIT for advanced adenomas was 
Table 3 Comparison of sensitivity and specificity of a FIT for detection of CRC and advanced adenomas in males and females at different cut-off values

\begin{tabular}{|c|c|c|c|c|c|c|c|c|c|c|c|}
\hline \multirow{2}{*}{$\begin{array}{l}\text { CRC } \\
\text { Sensitivity }\end{array}$} & & & & & & \multicolumn{6}{|c|}{ Advanced adenoma } \\
\hline & & & & & & Sensitivity & & & & & \\
\hline FIT cut-off & Total $\mathrm{N}=69^{*}$ & Males $\mathrm{N}=45^{*}$ & Females $\mathrm{N}=24^{*}$ & Difference & $p$-value & FIT cut-off & Total $\mathrm{N}=304^{\dagger}$ & Males $\mathrm{N}=164^{\dagger}$ & Females $\mathrm{N}=140^{\dagger}$ & Difference & p-value \\
\hline 50 ng/ml (Cl) & $88.4 \%$ (78-95) & $93.3 \%$ (82-99) & $79.2 \%(58-93)$ & $14.1 \%$ & 0.12 & $50 \mathrm{ng} / \mathrm{ml}(\mathrm{Cl})$ & $34.9 \%(30-41)$ & $36.6 \%$ (39-45) & $32.9 \%(25-41)$ & $3.7 \%$ & 0.55 \\
\hline 75 ng/ml (Cl) & $85.5 \%$ (75-93) & $93.3 \%$ (82-99) & $70.8 \%(49-87)$ & $22.5 \%$ & 0.03 & $75 \mathrm{ng} / \mathrm{ml}(\mathrm{Cl})$ & $30.9 \%(26-37)$ & $32.9 \%(26-41)$ & $28.6 \%(21-37)$ & $4.3 \%$ & 0.46 \\
\hline 100 ng/ml (Cl) & $85.5 \%$ (75-93) & 93.3\% (82-99) & $70.8 \%$ (49-87) & $22.5 \%$ & 0.03 & 100 ng/ml (Cl) & $28.6 \%(24-34)$ & $31.7 \%(25-39)$ & $25.0 \%(18-33)$ & $6.7 \%$ & 0.21 \\
\hline 200 ng/ml (Cl) & $75.4 \%(64-85)$ & $80.0 \%(65-90)$ & $66.7 \%(45-84)$ & $13.3 \%$ & 0.25 & 200 ng/ml (Cl) & $21.1 \%(17-26)$ & $24.4 \%(18-32)$ & $17.1 \%(11-24)$ & $7.3 \%$ & 0.16 \\
\hline Specificity & & & & & & Specificity & & & & & \\
\hline FIT cut-off & Total $\mathrm{N}=2,953^{\#}$ & Males $\mathrm{N}=1,312^{\#}$ & Females $\mathrm{N}=1,641^{\#}$ & Difference & $p$-value & FIT cut-off & Total $\mathrm{N}=\mathbf{2 , 6 4 9 ^ { \ddagger }}$ & Males $\mathrm{N}=1,148^{\ddagger}$ & Females $\mathrm{N}=1,501^{\ddagger}$ & Difference & p-value \\
\hline 50 ng/ml (Cl) & $89.5 \%(88-91)$ & $87.3 \%(85-89)$ & $91.2 \%$ (90-93) & $-3,9 \%$ & $<0,05$ & $50 \mathrm{ng} / \mathrm{ml}(\mathrm{Cl})$ & $92.3 \%(91-93)$ & $90.8 \%$ (89-92) & 93.4\% (92-95) & $-2.6 \%$ & $<0.05$ \\
\hline 75 ng/ml (Cl) & $91.5 \%$ (90-95) & $90.1 \%(88-92)$ & $92.6 \%(91-94)$ & $-2,5 \%$ & $<0,05$ & 75 ng/ml (Cl) & $94.0 \%(93-95)$ & $93.4 \%(92-95)$ & $94.5 \%$ (93-96) & $-1.1 \%$ & 0.22 \\
\hline 100 ng/ml (Cl) & $92.6 \%$ (92-94) & $91.2 \%$ (90-93) & $93.7 \%$ (92-95) & $-2,5 \%$ & $<0,05$ & 100 ng/ml (Cl) & $95.0 \%$ (94-96) & $94.4 \%$ (93-96) & $95.5 \%$ (94-97) & $-1.1 \%$ & 0.24 \\
\hline 200 ng/ml (Cl) & $94.8 \%$ (94-96) & $93.6 \%(21-95)$ & $95.8 \%$ (95-97) & $-2,2 \%$ & $<0,05$ & 200 ng/ml (Cl) & $96.6 \%(96-97)$ & $96.2 \%$ (95-97) & $97.0 \%$ (96-98) & $-0.8 \%$ & 0.28 \\
\hline
\end{tabular}

${ }^{*}$ This concerns the total of subjects with CRC from which the sensitivity was calculated. ${ }^{*}$ This concerns the total of subjects without CRC from which the specificity was calculated. ${ }^{\dagger}$ This concerns the total of subjects with advanced adenoma from which the sensitivity was calculated. ${ }^{\mp}$ This concerns the total of subjects without CRC and without advanced adenomas from which the specificity was calculated. FIT = faecal immunochemical test; $\mathrm{CRC}=$ colorectal cancer; $\mathrm{Cl}=$ confidence interval. 


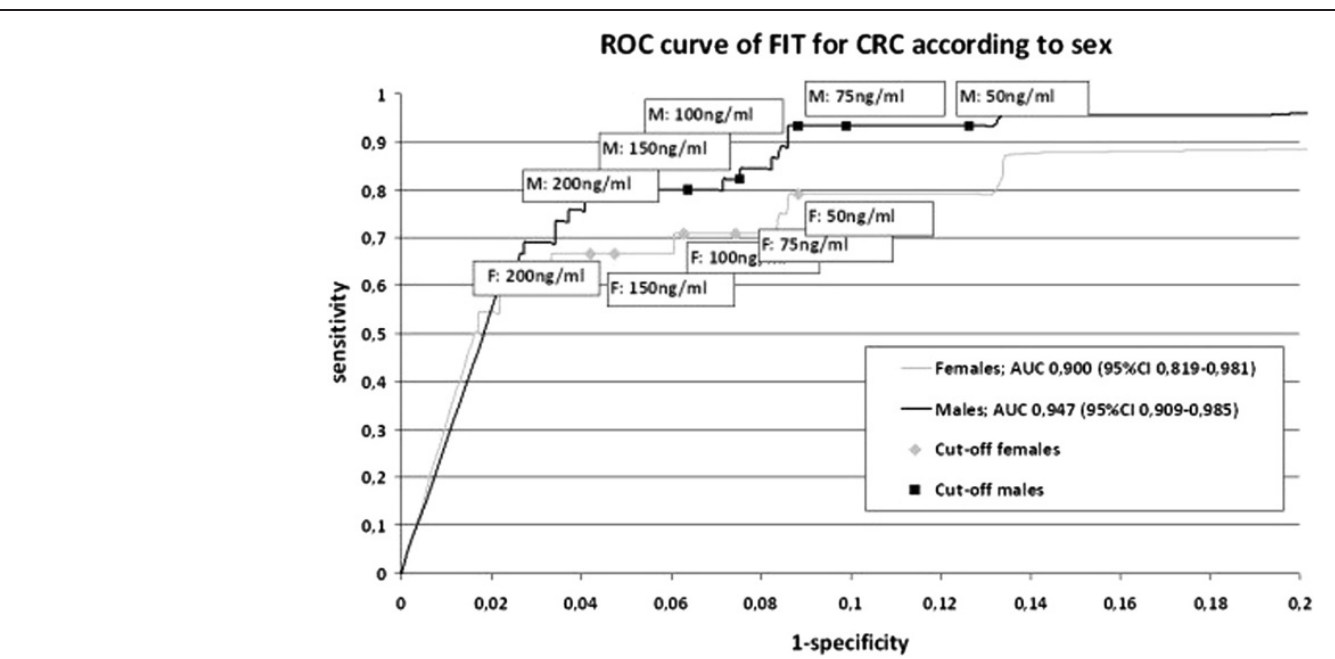

Figure 2 Receiver operating characteristic curve of FIT for detection of CRC. ROC = receiver operating characteristic; FIT = faecal immunochemical test; $C R C=$ colorectal cancer; $A \cup C=$ area under the curve.

slightly higher in males (not significant) and strongly related to size and the number of advanced adenomas.

In males, FIT was found to have $13-23 \%$ higher sensitivity for CRC than in females. Previous studies already found a difference in test performance for the detection of advanced neoplasia in males and females [3]. In the German study, positive and negative predictive values, as well as sensitivity and specificity were calculated. However, due to the inclusion of only 14 cases of CRC, test characteristics could not be calculated for CRC. The current study not only included a higher number of advanced adenomas, it also evaluated the relation between sex and FIT sensitivity for CRC, corrected for the location of colonic lesions and age of the participant. These variables were chosen because it is known that CRC develops earlier in lifetime in men then in women [12]. In addition, it is also known that females have a higher prevalence of right sided CRC [13]. Finally, left sided neoplasia have a higher likelihood to test positive on FIT $[9,14]$. A potential explanation for this phenomenon, could be a difference in degradation of haemoglobin between left and right sided lesions, or difference in shape and tendency to bleed between proximal and distal lesions [14].

In the multivariate analysis, location and sex were significantly associated with FIT sensitivity for CRC, but the univariate odds ratio for sex was not substantially affected by the inclusion of location and age in the analysis. By stratified analysis of $2 \times 2$ contingency tables, it

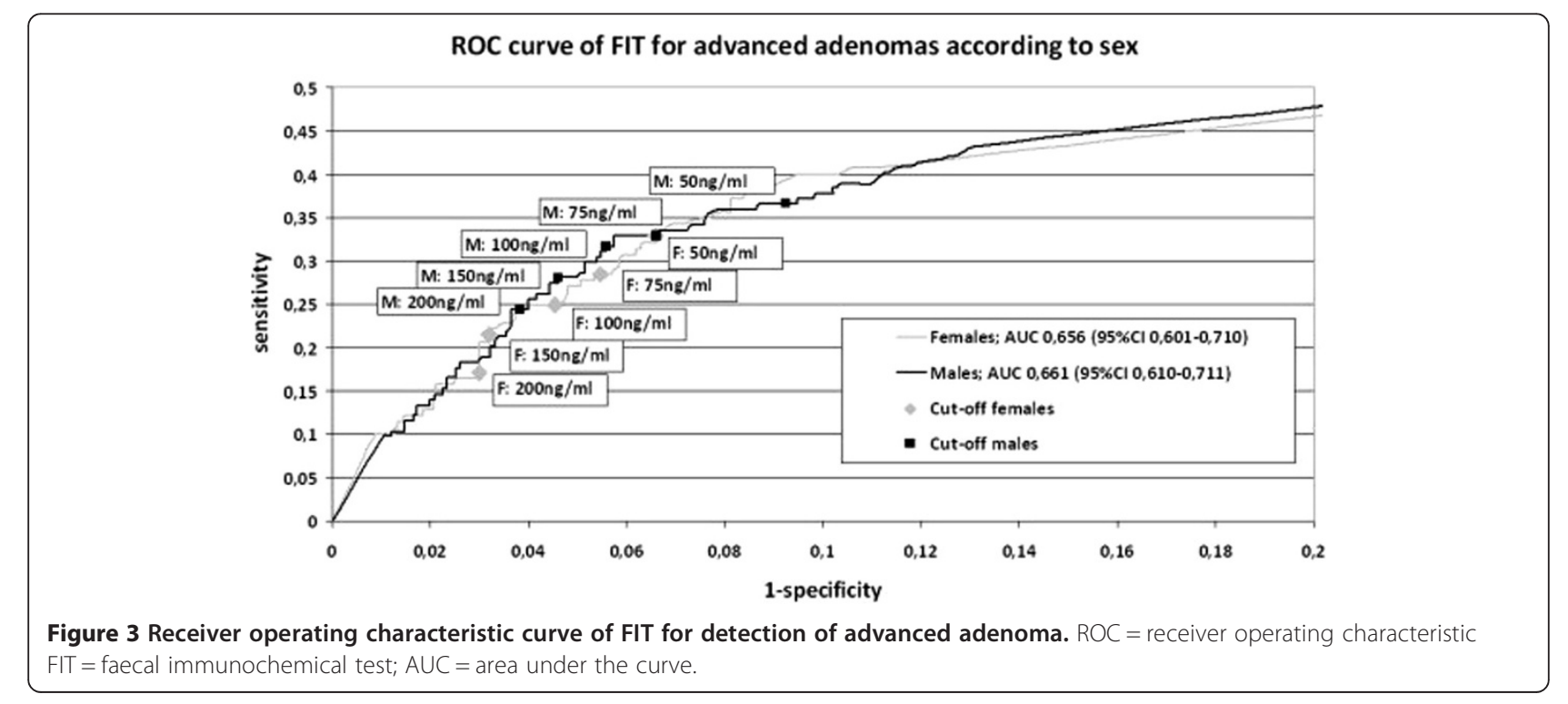


Table 4 Level of significance and odds ratio's for different variables used in a multivariate logistic regression model predicting sensitivity of a FIT at cut-off of $75 \mathrm{ng} / \mathrm{ml}$ for detection of CRC and advanced adenomas

\begin{tabular}{|c|c|c|c|c|c|c|c|c|c|}
\hline \multirow[b]{3}{*}{ Variable } & \multicolumn{4}{|l|}{ CRC } & \multirow[b]{3}{*}{ Variable } & \multicolumn{4}{|c|}{ Advanced adenoma } \\
\hline & \multicolumn{2}{|l|}{ Univariate model } & \multicolumn{2}{|l|}{ Multivariate model } & & \multicolumn{2}{|l|}{ Univariate model } & \multicolumn{2}{|l|}{ Multivariate model } \\
\hline & OR $(95 \% \mathrm{Cl})$ & p-value & OR $(95 \% \mathrm{Cl})$ & p-value & & OR $(95 \% \mathrm{Cl})$ & $\mathrm{p}$-value & OR $(95 \% \mathrm{Cl})$ & $\mathrm{p}$-value \\
\hline Sex (ref = female) $(N=69)$ & $5.77(1.33-24.95)$ & 0.02 & $6.16(1.15-32.92)$ & 0.03 & Sex (ref = female) $(N=304)$ & $1.23(0.75-2.00)$ & 0.41 & $1.00(0.57-1.75)$ & 0.99 \\
\hline Age (continuous variable) $(\mathrm{N}=69)$ & $1.01(0.94-1.08)$ & 0.89 & $1.00(0.92-1.08)$ & 0.96 & Age (continuous variable) $(\mathrm{N}=304)$ & $1.01(0.98-1.03)$ & 0.55 & $1.00(0.98-1.03)$ & 0.75 \\
\hline Location $($ ref $=$ right-sided) $(\mathrm{N}=68)$ & $4.30(1.07-17.35)$ & 0.04 & $4.83(0.95-24.8)$ & 0.05 & Location (ref = right-sdided $(\mathrm{N}=303$ ) & $1.94(1.26-2.98)$ & 0.002 & $1.31(0.79-2.20)$ & 0.30 \\
\hline T-stage $(r e f=T 1)(N=55)$ & $1.57(0.39-6.32)$ & 0.53 & $2.19(0.44-10.80)$ & 0.34 & AA size $(\mathrm{ref}=<10 \mathrm{~mm})(\mathrm{N}=285)$ & $5.58(2.55-12.22)$ & $<0.001$ & $5.24(2.32-11.83)$ & $<0.001$ \\
\hline Presence of AA (ref = none) $(\mathrm{N}=69)$ & $0.83(0.09-7.54)$ & 0.87 & $1.38(0.09-20.52)$ & 0.81 & Number of AA $(r e f=1)(N=300)$ & $4.82(2.63-8.85)$ & $<0.001$ & $4.27(2.10-8.70)$ & $<0.001$ \\
\hline
\end{tabular}

$\mathrm{FIT}=$ faecal immunochemical test; $\mathrm{CRC}=$ colorectal cancer; $\mathrm{AA}=$ advanced adenoma; $\mathrm{OR}=$ odds ratio; $\mathrm{Cl}=$ confidence interval. 
was found that the observed relation between sex and FIT sensitivity for CRC could not be explained by either location or age. It can only be speculated on whether the sex difference is due to other confounders, such as tumour size, tumour biology (e.g. blood vessel density), or colon transit time, which is known to be longer in females [15]. Other authors hypothesized that the higher serum concentration of haemoglobin in male blood could cause higher FIT positivity when blood is lost in the colon [3]. This cannot be confirmed in the current study, as the serum haemoglobin level of participants was not determined. For advanced adenomas, no significant difference in sensitivity was found between the sexes, but males consistently had a higher sensitivity. In multivariate analysis and stratified $2 \times 2$ contingency tables, it was found that the number and size of lesions are predictive for test sensitivity. This last observation is in line with another study that showed that the number and size of polyps influence test accuracy for detection of advanced adenomas [16].

Currently, CRC screening with preselection by means of FIT sampling is a one size fits all approach. Sex specific screening guidelines could be considered, in order to optimize the effectiveness of a screening programme in both males and females [3,17]. Based on the current results, the lower sensitivity of FIT in women could lead to a smaller benefit from screening for females. However, the lower sensitivity of FIT in females may be counterbalanced by a higher participation rate, as was found in the English and Scottish screening programmes $[18,19]$. Therefore, multiple factors need to be taken into account determine the efficiency of a CRC screening programme. When preferred, the same sensitivity for CRC could be easily reached by lowering the cut-off value in females. In the absence of a sex difference in the sensitivity for advanced adenomas, sex specific cut-off values in screening seem unnecessary, as prevalent cancers will presumably be detected in the first screening rounds. In the next screening rounds the focus of screening may shift to detection of advanced adenomas. In addition, individualising screening guidelines adds to the complexity of a screening programme and should only be adopted if the expected benefits are substantial. Individualized screening guidelines may confuse providers and consumers to the point of decreasing adherence [20].

The current study provides insight into the relation between sex and the test characteristics of FIT for detection of CRC and advanced adenomas. To the best of our knowledge, this is the first study to observe that sex specific differences in FIT sensitivity are mainly present in CRC and only small in advanced adenomas. Each participant in the study underwent complete colonoscopy regardless of FIT outcome. This enabled direct calculation of not only sensitivity but specificity as well. The high number of advanced colonic neoplasia in the referral population that was used, enabled us to stratify for CRC, which was not possible before [3].

For proper interpretation of the results, some limitations need to be discussed. The main limitation is that a heterogeneous population was studied. That is, both symptomatic subjects and subjects with higher than average risk for CRC (e.g. derived from adenoma and CRC surveillance programmes) were included. Consequently, it cannot be ruled out that, even after exclusion of subjects with anaemia and haematochezia, sensitivity may be overestimated and specificity underestimated due to work-up bias [21]. This may occur as symptomatic participants have an increased likelihood for having both a positive FIT and an advanced colorectal neoplasm. This is why the current study for instance did not aim to provide an optimal cut-off value for each sex in the screening setting. On the other hand, using nonscreening study populations to investigate test characteristics in subgroups that are usually underrepresented in screening studies seems justified. This is supported by a previous study that showed that CRC cases from a non screening setting had similar results as CRC cases from a screening study [22]. Another limitation it that location of lesions was assessed by the endoscopists by recognition of colonic landmarks. Although this is the most commonly used method for assessment of the location, the accuracy with which the location of the neoplastic lesions can be determined may not be optimal. In addition, as size of CRC was not prospectively scored, it was not possible to use this variable in the logistic regression analysis. Finally, there may be other explanatory variables for FIT performance that were not included, like for instance the use of NSAIDs [9].

\section{Conclusions}

In conclusion, males were found to have a higher FIT sensitivity and a lower specificity for CRC compared to females. However, as the shapes of and the areas under the ROC curves are similar, equal characteristics can be achieved by allowing different cut-off values for both sexes. Location of CRC and age of the individuals are not responsible for the observed differences in sensitivity. Whether the difference is relevant in screening remains questionable. No significant difference in test characteristics for advanced adenomas was found between the sexes.

\section{Additional file}

Additional file 1: Supplementary data.

\section{Abbreviations}

AUC: Area under the curve; Cl: Confidence interval; CRC: Colorectal cancer; FIT: Faecal immunochemical test; IBD: Inflammatory bowel disease; 
NSAIDs: Non Steroidal Anti Inflammatory Drugs; OR: Odds ratio; ROC: Receiver operating characteristic; T-stage: Tumor-stage.

\section{Competing interests}

The authors declare that they have no competing interests.

\section{Authors' contributions}

STT and FAO participated in the study concept and design; acquisition of data; analysis and interpretation of data, statistical analysis and drafting of the manuscript. RWMH participated in the study concept and design; acquisition of data analysis and interpretation and critical revision of the manuscript for important intellectual content and study supervision. APV and PS participated in the study concept and acquisition of data. JSTD participated in the study concept and design; acquisition and interpretation of data, and critical revision of the manuscript for important intellectual content. AAB participated in acquisition and interpretation of data, technical and material support. CJJM, GAM, LGMR and VMHC participated in the study concept and design; analysis and interpretation of data, critical revision of the manuscript for important intellectual content, and study supervision. All authors approved the final version of the article.

\section{Acknowledgements}

The authors gratefully acknowledge all participants and staff of the endoscopy units at the VU University Medical Centre, Kennemer Gasthuis Haarlem, Sint Lucas Andreas Hospital, Zaandam Medical Centre, and Slotervaart Hospital. Edwin van Hengel is especially acknowledged for an ongoing tremendous effort on test analysis.

Preliminary data of this study were presented at the Digestive Disease Week 2011 in Chicago.

S.T. van Turenhout and G.A. Meijer were supported by a research grand of the Centre for Translational Molecular Medicine (CTMM), the Netherlands. This foundation had no influence on any aspect relevant to this study. The OC sensor MICRO desktop analyser was provided by Eiken Chemical co., Tokyo, Japan. This company had no influence on any aspect relevant to this study.

\section{Author details}

'Department of Gastroenterology and Hepatology, VU University Medical Centre, Amsterdam, the Netherlands. ${ }^{2}$ Gastroenterology and Hepatology, Kennemer Gasthuis, Haarlem, the Netherlands. ${ }^{3}$ Gastroenterology and Hepatology, Sint Lucas Andreas Hospital, Amsterdam, the Netherlands. ${ }^{4}$ Clinical Chemistry, VU University Medical Centre, Amsterdam, the Netherlands. ${ }^{5}$ Pathology, VU University Medical Centre, Amsterdam, the Netherlands. ${ }^{6}$ Department for health evidence, Radboud University Medical Centre, Nijmegen, the Netherlands. ${ }^{7}$ Epidemiology and Biostatistics, VU University Medical Centre, Amsterdam, the Netherlands.

Received: 5 May 2014 Accepted: 11 December 2014

Published online: 21 December 2014

\section{References}

1. Siegel R, Naishadham D, Jemal A: Cancer statistics, 2012. CA Cancer J Clin 2012, 62:10-29.

2. Allison JE, Sakoda LC, Levin TR, Tucker JP, Tekawa IS, Cuff T, et al: Screening for colorectal neoplasms with new fecal occult blood tests: update on performance characteristics. J Natl Cancer Inst 2007, 99:1462-1470.

3. Brenner $H$, Haug $U$, Hundt $S$ : Sex differences in performance of fecal occult blood testing. Am J Gastroenterol 2010, 105:2457-2464.

4. Oort FA, Terhaar Sive Droste JS, VAN DER Hulst RW, VAN Heukelem HA, Loffeld $\mathrm{RJ}$, Wesdorp IC et al:: Colonoscopy controlled intraindividual comparisons to screen relevant neoplasia - fecal immunochemical test versus guaiac based fecal occult blood test. Aliment Pharmacol Ther 2010, 31(3):432-439.

5. Oort FA, van Turenhout ST, Coupe VM, van der Hulst RW, Wesdorp El, Terhaar Sive Droste JS, et al: Double sampling of a faecal immunochemical test is not superior to single sampling for detection of colorectal neoplasia: a colonoscopy controlled prospective cohort study. BMC Cancer 2011, 11:434

6. Terhaar Sive Droste JS, Oort FA, VAN DER Hulst RW, VAN Heukelem HA, Loffeld RJ, van Turenhout ST et al.: Higher Fecal Immunochemical Test cut-off levels: lower positivity rates but still acceptable detection rates for early stage colorectal cancers. Cancer Epidemiol Biomarkers Prev 2011, 20(2):272-280
7. Rozen P, Waked A, Vilkin A, Levi Z, Niv Y: Evaluation of a desk top instrument for the automated development and immunochemical quantification of fecal occult blood. Med Sci Monit 2006, 12:MT27-MT32.

8. Ciatto S, Martinelli F, Castiglione G, Mantellini P, Rubeca T, Grazzini G, et al: Association of FOBT-assessed faecal $\mathrm{Hb}$ content with colonic lesions detected in the Florence screening programme. Br J Cancer 2007, 96:218-221.

9. Haug U, Kuntz KM, Knudsen AB, Hundt S, Brenner H: Sensitivity of immunochemical faecal occult blood testing for detecting left- vs right-sided colorectal neoplasia. Br J Cancer 2011, 104:1779-1785.

10. Winawer SJ, Zauber AG, Ho MN, O'Brien MJ, Gottlieb LS, Sternberg SS, et al: The National Polyp Study. Eur J Cancer Prev 1993, 2(Suppl 2):83-87.

11. Rex DK, Kahi CJ, Levin B, Smith RA, Bond JH, Brooks D, et al: Guidelines for colonoscopy surveillance after cancer resection: a consensus update by the American Cancer Society and US Multi-Society Task Force on Colorectal Cancer. CA Cancer J Clin 2006, 56:160-167.

12. Ferlitsch M, Reinhart K, Pramhas S, Wiener C, Gal O, Bannert C, et al: Sex-specific prevalence of adenomas, advanced adenomas, and colorectal cancer in individuals undergoing screening colonoscopy. JAMA 2011, 306:1352-1358.

13. Benedix F, Kube R, Meyer F, Schmidt U, Gastinger I, Lippert H: Comparison of 17,641 patients with right- and left-sided colon cancer: differences in epidemiology, perioperative course, histology, and survival. Dis Colon Rectum 2010, 53:57-64.

14. Khalid-de Bakker CA, Jonkers DM, Sanduleanu S, de Bruine AP, Meijer GA Janssen JB, et al: Test performance of immunologic fecal occult blood testing and sigmoidoscopy compared with primary colonoscopy screening for colorectal advanced adenomas. Cancer Prev Res (Phila) 2011, 4:1563-1571.

15. Rao SS, Kuo B, McCallum RW, Chey WD, DiBaise JK, Hasler WL, et al: Investigation of colonic and whole-gut transit with wireless motility capsule and radiopaque markers in constipation. Clin Gastroenterol Hepatol 2009, 7:537-544.

16. Rozen P, Levi Z, Hazazi R, Waked A, Vilkin A, Maoz E, et al: Identification of colorectal adenomas by a quantitative immunochemical faecal occult blood screening test depends on adenoma characteristics, development threshold used and number of tests performed. Aliment Pharmacol Ther 2009, 29:906-917.

17. Wu D, Erwin D, Rosner GL: Estimating key parameters in FOBT screening for colorectal cancer. Cancer Causes Control 2009, 20:41-46.

18. Steele RJ, Kostourou I, McClements P, Watling C, Libby G, Weller D, et al: Effect of gender, age and deprivation on key performance indicators in a FOBTbased colorectal screening programme. J Med Screen 2010, 17:68-74.

19. von Wagner C, Baio G, Raine R, Snowball J, Morris S, Atkin W, Obichere A, Handley G, Logan RF, Rainbow S, Smith S, Halloran S, Wardle J: Inequalities in participation in an organized national colorectal cancer screening programme: results from the first 2.6 million invitations in England. Int J Epidemiol 2011, 40(3):712-8.

20. Lansdorp-Vogelaar I, Van Ballegooijen M, Zauber AG, Boer R, Wilschut J, Winawer SJ, et al: Individualizing colonoscopy screening by sex and race. Gastrointest Endosc 2009, 70:96-108. 108.

21. Imperiale TF: Quantitative immunochemical fecal occult blood tests: is it time to go back to the future? Ann Intern Med 2007, 146:309-311.

22. van Turenhout ST, van Rossum LG, Oort FA, Laheij RJ, van Rijn AF, Terhaar Sive Droste JS, et al: Similar fecal immunochemical test results in screening and referral colorectal cancer. World J Gastroenterol 2012, 18:5397-5403.

\section{Submit your next manuscript to BioMed Central and take full advantage of:}

- Convenient online submission

- Thorough peer review

- No space constraints or color figure charges

- Immediate publication on acceptance

- Inclusion in PubMed, CAS, Scopus and Google Scholar

- Research which is freely available for redistribution 